\title{
Quasielastic Neutron Scattering Study of Tetrahydroborate Anion Dynamical Perturbations in Sodium Borohydride due to Partial Halide Anion Substitution
}

Nina Verdal, ${ }^{1,2}$ Terrence J. Udovic, ${ }^{1, *}$ John J. Rush, ${ }^{1,2}$ and Alexander V. Skripov ${ }^{3}$

${ }^{1}$ NIST Center for Neutron Research, National Institute of Standards and Technology, Gaithersburg, MD 20899-6102, USA

${ }^{2}$ Department of Materials Science and Engineering, University of Maryland, College Park, MD 20742-2115, USA

${ }^{3}$ Institute of Metal Physics, Ural Branch of the Russian Academy of Sciences, Ekaterinburg 620990, Russia

\begin{abstract}
Equimolar $\mathrm{NaBH}_{4}-\mathrm{NaX}(\mathrm{X}=\mathrm{Cl}$ and I) solid solutions were synthesized to study, via quasielastic neutron scattering, the effect of partial halide anion substitution on the reorientational dynamics of tetrahydroborate $\left(\mathrm{BH}_{4}^{-}\right)$anions in $\mathrm{NaBH}_{4}$. The $\mathrm{BH}_{4}^{-}$reorientational mobility increased in the order of $\mathrm{NaBH}_{4}-\mathrm{NaCl}, \mathrm{NaBH}_{4}$, and $\mathrm{NaBH}_{4}-\mathrm{Nal}$, which corresponded with expanding face-centered-cubic lattices accommodating the respective increasing sizes of the $\mathrm{Cl}^{-}, \mathrm{BH}_{4}{ }^{-}$, and $\mathrm{I}^{-}$anions. The $\mathrm{BH}_{4}{ }^{-}$anions in $\mathrm{NaBH}_{4}-\mathrm{NaCl}$ were found (at least above $400 \mathrm{~K}$ ) to undergo 'cubic' tumbling motions with the four $\mathrm{H}$ atoms per anion visiting all eight corners of a cube, similar to what was previously observed for $\mathrm{NaBH}_{4}$. In contrast, the $\mathrm{BH}_{4}{ }^{-}$anions in $\mathrm{NaBH}_{4}{ }^{-}$ $\mathrm{Nal}$ were found to undergo something more akin to 'tetrahedral' tumbling motions, where the $\mathrm{H}$ atoms visit all four corners of a tetrahedron. Despite a noticeable softening of the $\mathrm{BH}_{4}{ }^{-}$ torsional energies with increasing lattice constant amongst $\mathrm{NaBH}_{4}$ and the two solid solutions, all three compounds exhibited similar activation energies for reorientation of about 11-12 kJ mol ${ }^{-1}$.
\end{abstract}

Keywords: complex hydrides; quasielastic neutron scattering; reorientational dynamics; sodium borohydride; sodium chloride; sodium iodide

\section{Introduction}

Compounds containing tetrahydroborate $\left(\mathrm{BH}_{4}{ }^{-}\right)$anions are potentially important materials for a variety of applications such as solid-state hydrogen storage [1] and fast-ion conduction [2]. Aside from their ionic character, such compounds often possess interesting 
molecular dynamics due to the propensity of the $\mathrm{BH}_{4}{ }^{-}$anions to undergo relatively facile reorientational motions, with jump frequencies that vary widely depending on their crystal environment and that can easily surpass $10^{12} \mathrm{~s}^{-1}$ at technologically relevant temperatures $[3,4,5]$. Often, their dynamical properties can be sensitive indicators of departures from bulk thermodynamic properties. For example, $\mathrm{LiBH}_{4}$ nanoconfined in a controlled-pore carbon framework was observed to exhibit two fractions of dynamically different $\mathrm{BH}_{4}^{-}$anions, one highly mobile fraction associated with $\mathrm{LiBH}_{4}$ near the pore interface and another slower, more bulk-like fraction in the interior of the pore [5,6]. In general, the ability to observe and differentiate such dynamical information can lead to an increased understanding of thermodynamic and kinetic phenomena of complex systems on a more fundamental molecular level.

In the present paper, we investigate by quasielastic neutron scattering (QENS) the perturbation to $\mathrm{BH}_{4}{ }^{-}$reorientational dynamics in the light-alkali-metal borohydride $\mathrm{NaBH}_{4}$ modified by partial halide $\left(\mathrm{Cl}^{-}\right.$and $\mathrm{I}^{-}$) anion substitution. Analogous studies on hexagonal $\mathrm{LiBH}_{4}$ diluted with Lil have suggested similar reorientational mechanisms for both neat and partially iodide-substituted $\mathrm{LiBH}_{4}$, (i.e., rapid diffusive-like reorientational jumps of three $\mathrm{H}$ atoms around the local $\mathrm{BH}_{4}{ }^{-}$trigonal axis concomitant with slower jump exchanges of these $\mathrm{H}$ atoms with the fourth axial $\mathrm{H}$ atom) but with increased $\mathrm{BH}_{4}{ }^{-}$anion reorientational mobility for the latter iodide-substituted compounds $[7,8]$.

$\mathrm{NaBH}_{4}$ is known to undergo an order-disorder transition near $190 \mathrm{~K}$ [9]. Below this temperature, the compound exhibits a tetragonal lattice with orientationally ordered $\mathrm{BH}_{4}^{-}$ anions. Above this temperature, it transforms to a face-centered-cubic (fcc) structure with orientationally disordered $\mathrm{BH}_{4}{ }^{-}$anions $[10,11]$. Each anion possesses two equally probable orientations superimposed to form a cube of eight $\mathrm{H}$ atoms, each with $50 \%$ occupancy, with a $\mathrm{B}$ atom at the center. Partial substitution of the $\mathrm{BH}_{4}{ }^{-}$anions with either $\mathrm{Cl}^{-}$or $\mathrm{I}^{-}$anions leads to a disordered fcc solid solution phase $[12,13,14]$ (see Fig. 1). At these high halide concentrations and in the absence of an ordered sublattice of $\mathrm{BH}_{4}^{-}$and halide anions, it is reasonable to assume that the disordered solid-solution phase will already be comprised of both significant substitutional and orientational disorder at the lowest temperatures, precluding any possible further entropically driven order-disorder transition such as occurs for pure $\mathrm{NaBH}_{4}$ at higher temperatures. The respective room-temperature cubic $\mathrm{NaCl}, \mathrm{NaBH}_{4}$, and $\mathrm{Nal}$ lattice constants of $5.642 \AA$ [12], $6.157 \AA$ [14], and $6.469 \AA$ [14] reflect the VI-coordinate Shannon crystal radius of the $\mathrm{Na}^{+}$cation $(1.16 \AA)$ and the relative increase in the Shannon crystal radii of the anions from $\mathrm{Cl}^{-}(1.67 \AA)$ to $\mathrm{BH}_{4}^{-}(1.92 \AA)$ to I' $(2.06 \AA)[15,16]$. Hence, partial $\mathrm{Cl}^{-}$and I' substitution leads solid-solution compounds with respectively smaller and larger lattice constants than for $\mathrm{NaBH}_{4}$, which may impact $\mathrm{BH}_{4}{ }^{-}$reorientational mechanism and mobility. 


\section{Materials and Methods}

All sample manipulations were performed inside a He-filled glovebox. Equimolar $\mathrm{Na}^{11} \mathrm{BH}_{4}-\mathrm{NaX}(\mathrm{X}=\mathrm{Cl}$ and I) solid solutions were synthesized by ball-milling 1:1 mixtures of $\mathrm{Na}^{11} \mathrm{BH}_{4}$ (Katchem [17]) and $\mathrm{NaX}(\mathrm{NaCl}$ and $\mathrm{Nal}$, both $\geq 99.5 \%$, Aldrich) under a He atmosphere using a Fritsch Pulverisette no. 7 ball mill. ${ }^{11} \mathrm{~B}$-enriched $\mathrm{NaBH}_{4}$ was used to avoid the large neutron absorption cross section of ${ }^{10} \mathrm{~B}$ present in natural boron. (N.B., we have dropped the isotope designation throughout the rest of this paper for simplicity.) Eight $10 \mathrm{~mm}$ diameter stainless steel balls were used in a $12 \mathrm{ml}$ stainless steel jar with a sample-to-ball mass ratio of either 1:30 $\left(\mathrm{NaBH}_{4}-\mathrm{Nal}\right)$ or 1:20 $\left(\mathrm{NaBH}_{4}-\mathrm{NaCl}\right)$. For $\mathrm{NaBH}_{4}-\mathrm{Nal}$, the $4 \mathrm{~h}$ total processing time was comprised of a repetitive two-step sequence: i.e., 2 min with the mill on $(200 \mathrm{~Hz})$ followed by 2 min with the mill off. For $\mathrm{NaBH} 4-\mathrm{NaCl}$, the $24 \mathrm{~h}$ total processing time consisted of cycles of 5 min milling with 2 min rest. After milling, the samples were annealed for $4 \mathrm{~d}$ at $533 \mathrm{~K}$ in an inert He gas environment. The homogeneities of the resulting solid solutions were confirmed by $x-$ ray powder diffraction (XRD) using a Rigaku Ultima III X-ray diffractometer with a Cu-K $\alpha$ source. For neutron scattering measurements, all samples were loaded into annular-shaped Al foil packets (yielding close to $10 \%$ scatterers) and further sealed inside cylindrical Al cells. During measurements, temperatures were regulated with a He closed-cycle refrigerator.

All neutron scattering measurements were performed at the NIST Center for Neutron Research. Neutron elastic scattering fixed-window scans (FWSs) (and QENS spectra for $\mathrm{NaBH}_{4}{ }^{-}$ Nal) were collected on the High-Flux Backscattering Spectrometer (HFBS) [18], which operates at an incident neutron wavelength of $6.27 \AA$ and an instrumental resolution of about $0.8 \mu \mathrm{eV}$ full width at half maximum (FWHM). Each displayed FWS was formed by summing over all detectors for a total momentum transfer $(Q)$ range of $0.2 \AA^{-1}<Q<1.75 \AA^{-1}$. QENS spectra were also collected on the Disk-Chopper Time-of-Flight Spectrometer (DCS) [19] using incident neutron wavelengths of $6 \AA$, yielding an instrumental resolution of $30 \mu \mathrm{eV} \mathrm{FWHM}$ and a maximum $Q$ value of $1.97 \AA^{-1} ; 4.1 \AA$, yielding an instrumental resolution of $80 \mu \mathrm{eV} F W H M$ and a maximum $Q$ value of $2.88 \AA^{-1}$; and $2.75 \AA$, yielding an instrumental resolution of $275 \mu \mathrm{eV} \mathrm{FWHM}$ and a maximum $Q$ value of $4.29 \AA^{-1}$. Neutron vibrational spectra were obtained on the FilterAnalyzer Neutron Spectrometer (FANS) [20] using both the pyrolytic graphite $P G(002)$ and $\mathrm{Cu}(220)$ monochromators to cover the neutron energy transfer ranges of 10-32 meV and 32$180 \mathrm{meV}$, respectively. Horizontal collimations of $20^{\prime}$ of arc were used before and after the monochromator. Instrumental resolutions varied from around $1.2 \mathrm{meV}$ FWHM below $32 \mathrm{meV}$ to about $3 \%$ of the energy transfer above $32 \mathrm{meV}$. The neutron scattering data were reduced and analyzed using the DAVE [21] software package. The unit cell schematic was created with the VESTA software package [22]. All error bars in the figures denote $\pm 1 \sigma$.

\section{Quasielastic Neutron Scattering Methodology}


In a QENS experiment, monoenergetic neutrons are impinged onto a sample and the energies and intensities of the resulting scattered neutrons near zero energy transfer are measured as a function of $Q$. Ideally, the elastically scattered neutrons would yield a delta function at zero energy transfer, but in reality, this function is convoluted with the instrumental resolution function and is more Gaussian-like. Since the incoherent neutron scattering cross section for hydrogen is much higher than other elements, scattering due to $\mathrm{H}$ atoms will dominate the observed incoherent scattering intensity (between the Bragg peaks). For the compounds under consideration, we only have to consider the scattering from the $\mathrm{H}$ atoms associated with the $\mathrm{BH}_{4}{ }^{-}$anions. At low temperatures, the $\mathrm{BH}_{4}{ }^{-}$anions are relatively immobile with respect to the instrumental resolution, and the incoherent scattering from the $\mathrm{H}$ atoms yields only an elastic peak. As the temperature is increased, the reorientational jump rates of the $\mathrm{BH}_{4}{ }^{-}$anions increase to the point that the neutron is able to 'sense' these motions and a portion of the elastic peak begins to broaden into one or more Lorentzian components (quasielastic scattering), the number and fraction depending on the reorientational mechanism. As the temperature increases further, the quasielastic scattering becomes ever broader and eventually collapses into the baseline, leaving only the elastic component observable.

One useful QENS measurement on a backscattering spectrometer such as HFBS is a fixed window scan (FWS), where we record the scattering intensity at zero energy transfer as a function of temperature. FWSs are useful, in general, for establishing the relative mobilities of hydrogenous species in different solid-state materials [23]. At the lower temperatures, if the reorientational jump rates of the $\mathrm{BH}_{4}^{-}$anions are less than about $10^{8} \mathrm{~s}^{-1}$, no quasielastic broadening is observable, all of the scattering is elastic, and the FWS intensity will be relatively high. In this temperature region, there is only a gradual drop due to the effect of the DebyeWaller factor. As the temperature is raised further, the jump frequencies eventually become greater than $10^{8} \mathrm{~s}^{-1}$, some of the elastic peak intensity becomes quasielastic (i.e., broadened) and the resulting FWS intensity will begin to decrease significantly until the quasielastic component disappears into the baseline (at jump rates $>10^{10} \mathrm{~s}^{-1}$ ). At this point, only the elastic component remains, and the reduced FWS intensity again continues its gradual drop with further increases in temperature.

In addition to what we learn from FWS measurements, we can potentially determine the $\mathrm{BH}_{4}^{-}$reorientational mechanism by analyzing, in detail, the $Q$ dependence of the QENS spectra. Typically, we calculate the elastic incoherent structure factor (EISF) as a function of $Q$, which is defined as the ratio of purely elastic scattering intensity to the total scattering intensity (i.e., elastic + quasielastic scattering intensity). The EISF functional behavior with $Q$ is sensitive to the reorientational mechanism. By plotting EISF versus $Q$ and comparing to different reorientational model functions, we can often draw reasonable conclusions concerning the predominant reorientational mechanism. 
Finally, as the quasielastic linewidth is a measure of the jump rate, by plotting the linewidth versus inverse temperature in an Arrhenius fashion, we can obtain the activation energy for reorientation $E_{a}$ from the slope of $E_{a} / k$, where $k$ is Boltzmann's constant.

\section{Results and Discussion}

Figure 2 displays a comparison of the FWSs for $\mathrm{NaBH}_{4}-\mathrm{NaCl}$ and $\mathrm{NaBH}_{4}-\mathrm{Nal}$. Since pure $\mathrm{NaBH}_{4}$ is in its ordered tetragonal structure below $190 \mathrm{~K}$, it is only meaningful to compare the FWS of the two isotypic, disordered cubic mixed compounds below this temperature. For the best comparison, the scans were rescaled and shifted appropriately to line up the intensities for the two compounds at both the lowest and highest temperatures in order to correct for differences in sample size and any intensity variations due to possible differences in reorientational mechanisms. It is seen that, as the anion size increases, the reorientational jump rate increases at a given temperature (thus lowering the elastic scattering intensity), and the temperature corresponding to the onset of rapid reorientations decreases. Hence, there is a likely trend in relative $\mathrm{BH}_{4}{ }^{-}$mobilities with lattice constant. In particular, between the two mixed compounds, $\mathrm{BH}_{4}{ }^{-}$is relatively less mobile in $\mathrm{NaBH}_{4}-\mathrm{NaCl}$ where the lattice is relatively smaller. This makes sense sterically, since a larger lattice translates to a larger interstitial volume and less constrictive nearest-neighbor interactions, on average, for the rotating $\mathrm{BH}_{4}{ }^{-}$ anions. This is consistent with what is observed for hexagonal $\mathrm{LiBH}_{4}$ with or without partial I' anion substitution $[8,24,25]$. This trend with lattice size also agrees with the relative $\mathrm{BH}_{4}{ }^{-}$ mobilities observed for the series of alkali-metal borohydrides [23]. It should be noted that no FWS discontinuity due to an order-disorder phase transition, as seen for $\mathrm{NaBH}_{4}$ at $190 \mathrm{~K}$ [23], is evident for the two solid-solution compounds.

Figure 3 compares the EISFs determined from DCS data measured out to $Q$ values of $4.29 \AA^{-1}$ for $\mathrm{NaBH}_{4}-\mathrm{NaCl}$ and $\mathrm{NaBH}_{4}-\mathrm{Nal}$ at several higher temperatures corresponding to similar quasielastic linewidths (i.e., reorientational jump frequencies on the order of $10^{12} \mathrm{~s}^{-1}$ ), with model curves corresponding to various reorientational mechanisms. Here we consider only physically reasonable models for the particular $\mathrm{BH}_{4}{ }^{-}$site geometry, namely, (i) two-fold and three-fold reorientational jumps around a single symmetry axis, (ii) reorientational jumps amongst the four corners of a tetrahedron (tetrahedral tumbling); (iii) reorientational jumps amongst the eight corners of a cube (cubic tumbling); and (iv) isotropic rotational diffusion. The functional forms for these reorientational models are described in the Appendix. For $\mathrm{NaBH}_{4}-\mathrm{NaCl}$, the data suggest that the $\mathrm{BH}_{4}{ }^{-}$anions are undergoing a reorientational mechanism approaching cubic tumbling. This is consistent with what has been previously observed for $\mathrm{BH}_{4}^{-}$ reorientations in disordered $\mathrm{NaBH}_{4}[26,27]$, where diffraction indeed indicates a cubic arrangement of $\mathrm{H}$ atom positions around each $\mathrm{B}$ atom. 
Interestingly, the situation for $\mathrm{NaBH}_{4}-\mathrm{Nal}$ is somewhat different. The EISF data for this compound suggest that the $\mathrm{BH}_{4}{ }^{-}$anions are undergoing predominantly tetrahedral tumbling, although the downward trend of the datapoints also suggests that the anions are starting to experience some cubic tumbling on the resolution timescale of the instrument. This is not inconsistent with the notion of a diffraction-average cubic $\mathrm{H}$ atom arrangement around each $\mathrm{B}$ atom. Diffraction only gives a composite snapshot of the $\mathrm{BH}_{4}{ }^{-}$anion orientations averaged over all unit cells and provides no information concerning the dynamical evolution of individual $\mathrm{BH}_{4}{ }^{-}$ anions. QENS fills in this gap. For $\mathrm{NaBH}_{4}-\mathrm{NaCl}$ and $\mathrm{NaBH}_{4}, \mathrm{QENS}$ tells us that the $\mathrm{H}$ atoms from individual $\mathrm{BH}_{4}{ }^{-}$anions tend to tumble, for the most part, amongst the eight corners of a cube, at least on the DCS timescale. In contrast, for $\mathrm{NaBH}_{4}-\mathrm{Nal}, \mathrm{H}$ atoms from individual $\mathrm{BH}_{4}{ }^{-}$anions seem to more often favor a particular crystallographic orientation within the lattice, jumping amongst tetrahedral corners a number of times before changing their preferred orientation to the other disordered crystallographic orientation, after which they commence a new series of teterahedral tumbling motions. Together these two crystallographic orientations yield a diffraction-average cube of $\mathrm{H}$ atoms. Yet, on the DCS timescale, these orientations are 'dynamically' separate since the instrument cannot detect the much slower jumps between the two configurations.

We again note that the predominant mechanisms for these two solid-solution compounds are compared at similar jump frequencies but at only one overlapping temperature of $400 \mathrm{~K}$. It would be interesting to extend these EISF measurements for both compounds down to lower temperatures at lower jump frequencies to more thoroughly document the temperature-dependent progression, if any, of the respective reorientational mechanisms. Since we have only made high- $Q$ measurements at these higher temperatures to date, further measurements are needed. Indeed, the mechanistic differences between the two halidesubstituted compounds are intriguing and worthy of future investigation.

Figure 4 illustrates the Arrhenius plots of linewidth vs. inverse temperature for all three compounds (in the same disordered cubic structure) from the QENS data. The relative vertical line shifts reflect the relative mobilities of the compounds as inferred by the FWSs in Fig. 2. There is roughly a factor of two difference in reorientational rates between $\mathrm{NaBH}_{4}-\mathrm{NaCl}$ and $\mathrm{NaBH}_{4}-\mathrm{Nal}$, with intermediate rates observed for $\mathrm{NaBH}_{4}$. It is interesting that the activation energy for reorientation $E_{a}$ is found to be very similar for each compound: $11.1(4) \mathrm{kJ} \mathrm{mol}^{-1}$ [114(4) meV], 11.9(5) kJ mol${ }^{-1}$ [123(5) meV], and 11.7(3) $\mathrm{kJ} \mathrm{mol}^{-1}$ [121(3) meV] for $\mathrm{NaBH}_{4}-\mathrm{NaCl}_{\text {, }}$ $\mathrm{NaBH}_{4}$ [27], and $\mathrm{NaBH}_{4}-\mathrm{Nal}$, respectively. This seems somewhat surprising since one might reasonably expect a larger, less constrictive $\mathrm{BH}_{4}{ }^{-}$anion interstitial site to have a lower barrier to reorientation. Indeed, the neutron vibrational spectra of the three compounds in Fig. 5, although measured at $4 \mathrm{~K}$ where there is more of a propensity for orientational ordering and zero reorientational mobility on a neutron timescale, nonetheless indicate some softening of 
the $\mathrm{BH}_{4}{ }^{-}$torsional bands between $30 \mathrm{meV}$ and $60 \mathrm{meV}$ and of the $\mathrm{BH}_{4}{ }^{-}$bending modes between $130 \mathrm{meV}$ and $170 \mathrm{meV}$, as expected for increasing lattice size going from $\mathrm{NaBH}_{4}-\mathrm{NaCl}$ to $\mathrm{NaBH}_{4}$ to $\mathrm{NaBH}_{4}$-Nal. Apparently, differences in the curvature near the bottom of the $\mathrm{H}$ potential well, which lead to minor variations in the phonon energies, may not be predicative of differences in the curvature higher up the potential well or in the ultimate barrier height. First-principles calculations are needed to investigate this phenomenon in more detail.

It should be noted that, because these solid-solution compounds are disordered, they will possess a distribution of $\mathrm{BH}_{4}{ }^{-}$environments, each with its own potential energy landscape. Therefore, there is most likely a distribution of phonon energies, jump rates, and activation energy barriers to consider, and the present results represent average values of these parameters. Indeed, there is evidence in Fig. 5 of broadened $\mathrm{BH}_{4}{ }^{-}$torsional energy bands for $\mathrm{NaBH}_{4}-\mathrm{NaCl}$ and $\mathrm{NaBH}_{4}-\mathrm{Nal}$ compared to that of $\mathrm{NaBH}_{4}$ due to the inherent lattice disorder of these solid-solution compounds. Thus one should be somewhat cautious of overinterpreting the QENS-derived activation energies, since it assumes that the QENS spectra capture the entire distribution of quasielastic scattering linewidths at each temperature with a single "distribution-averaged" Lorentzian that reflects the average reorientational mobility. This may not be entirely accurate. Even with the expected distribution of anion site environments in these compounds, it is still noteworthy that we are able to perform a reasonable mechanistic analysis of the reorientational dynamics using the average jump rates derived from QENS measurements.

\section{Conclusions}

We have shown by QENS measurements that $\mathrm{BH}_{4}{ }^{-}$reorientational mobility in the hightemperature disordered phase of $\mathrm{NaBH}_{4}$ was perturbed by partial substitution of the $\mathrm{BH}_{4}{ }^{-}$anion with either smaller $\mathrm{Cl}^{-}$or larger $\mathrm{I}^{-}$anions. The increase in $\mathrm{BH}_{4}{ }^{-}$anion mobility correlated with an increase in the fcc lattice constant (i.e., an increase in the available $\mathrm{BH}_{4}{ }^{-}$site volume) due to the corresponding average sizes of the anions. Some differences in $\mathrm{BH}_{4}{ }^{-}$reorientational mechanisms were observed for $\mathrm{NaBH}_{4}-\mathrm{NaCl}$ and $\mathrm{NaBH}_{4}-\mathrm{Nal}$ in the mobility region of $10^{12}$ jumps s${ }^{-1}$, the former displaying more cubic tumbling behavior, similar to that of $\mathrm{NaBH}_{4}$, and the latter more tetrahedral tumbling behavior. $\mathrm{NaBH}_{4}-\mathrm{NaCl}, \mathrm{NaBH}_{4}$, and $\mathrm{NaBH}_{4}-\mathrm{Nal}$ all displayed similar QENS-derived activation energies for reorientation (11-12 $\mathrm{kJ} \mathrm{mol}^{-1}$ ). Spectral smearing of the $\mathrm{BH}_{4}{ }^{-}$torsional vibrational bands for the mixed compounds compared to that for $\mathrm{NaBH}_{4}$ corroborated the substitutionally disordered nature of the mixed compounds. The results of additional high- $Q$ measurements at lower temperatures and mobilities for the mixed compounds, as well as a comparison of all QENS results with those from complementary NMR measurements are forthcoming.

\section{Appendix}


The following equations describe the $Q$-dependence of the EISF for different $\mathrm{BH}_{4}{ }^{-}$reorientation mechanisms considered in the text, assuming a perfect $\mathrm{BH}_{4}^{-}$tetrahedron with a $\mathrm{B}-\mathrm{H}$ bond distance $d_{\mathrm{B}-\mathrm{H}}=1.22 \AA$ and an $\mathrm{H}-\mathrm{H}$ bond distance $d_{\mathrm{H}-\mathrm{H}}=1.99 \AA$ [27] $\left(N . B ., d_{\mathrm{H}-\mathrm{H}}=(8 / 3)^{1 / 2} d_{\mathrm{B}-\mathrm{H}}\right)$, and where $j_{0}(x)=\sin (x) / x$ :

For two-fold or three-fold reorientational jumps around a single respective $C_{2}$ or $C_{3}$ anion symmetry axis [28]:

$$
\mathrm{EISF}=\frac{1}{2}\left[1+j_{0}\left(Q d_{\mathrm{H}-\mathrm{H}}\right)\right]
$$

For reorientational jumps amongst the four corners of a tetrahedron (tetrahedral tumbling) [29]:

$$
\mathrm{EISF}=\frac{1}{4}\left[1+3 j_{0}\left(Q d_{\mathrm{H}-\mathrm{H}}\right)\right] .
$$

For reorientational jumps amongst the eight corners of a cube (cubic tumbling) [30]:

$$
\mathrm{EISF}=\frac{1}{8}\left[1+3 j_{0}\left(\frac{2}{\sqrt{3}} Q d_{\mathrm{B}-\mathrm{H}}\right)+3 j_{0}\left(Q d_{\mathrm{H}-\mathrm{H}}\right)+j_{0}\left(2 Q d_{\mathrm{B}-\mathrm{H}}\right)\right] .
$$

Finally, for isotropic rotational diffusion on the surface of a sphere with radius $d_{\mathrm{B}-\mathrm{H}}$ [28]:

$$
\mathrm{EISF}=j_{0}^{2}\left(Q d_{\mathrm{B}-\mathrm{H}}\right) .
$$

\section{Acknowledgements}

This work was partially supported by the DOE EERE under Grant No. DE-EE0002978, the Russian Foundation for Basic Research under Grant No. 12-03-00078, the U.S. Civilian Research \& Development Foundation (CRDF Global) under Award No. RUP1-7076-EK-12, and the National Science Foundation under Cooperative Agreement No. OISE-9531011. This work utilized facilities supported in part by the National Science Foundation under Agreement DMR0944772.

\section{References}

[1] V. Stavila, L. Klebanoff, J. Vajo, P. Chen, Development of On-Board Reversible Complex Metal Hydrides for Hydrogen Storage, in: L. Klebanoff (Ed.), Hydrogen Storage Technology: Materials and Applications, CRC Press, Boca Raton, 2013, pp 133-211.

[2] A. Unemoto, M. Matsuo, S. Orimo, Adv. Funct. Mater. 24 (2014) 2267-2279.

[3] A. Remhof, Z. Łodziana, P. Martelli, O. Friedrichs, A. Züttel, A. V. Skripov, J. P. Embs, T. Strässle, Phys. Rev. B 81 (2010) 214304. 
[4] D. Blanchard, J. B. Maronsson, M. D. Riktor, J. Kheres, D. Sveinbjörnsson, E. Gil Bardají, A. Léon, F. Juranyi, J. Wuttke, K. Lefmann, B. C. Hauback, M. Fichtner, T. Vegge, J. Phys. Chem. C 116 (2012) 2013-2023.

[5] N. Verdal, T. J. Udovic, J. J. Rush, X. Liu, E. H. Majzoub, J. J. Vajo, A. F. Gross, J. Phys. Chem. C 117 (2013) 17983-17995.

[6] X. Liu, E. H. Majzoub, V. Stavila, R. K. Bhakta, M. D. Allendorf, D. T. Shane, M. S. Conradi, N. Verdal, T. J. Udovic, S.-J. Hwang, J. Mater. Chem. A 1 (2013) 9935-9941.

[7] N. Verdal, T. J. Udovic, J. J. Rush, J. Phys. Chem. C 116 (2012) 1614-1618; ibid. 5275-5275.

[8] N. Verdal, T. J. Udovic, J. J. Rush, H. Wu, A. V. Skripov, J. Phys. Chem. C 117 (2013) 1201012018.

[9] W. H. Stockmayer, C. C. Stephenson, J. Chem. Phys. 21 (1953) 1311-1312.

[10] P. Fisher, A. Züttel, Mater. Sci. Forum 443-444 (2004) 287-290.

[11] G. Renaudin, S. Gomes, H. Hagemann, L. Keller, K. Yvon, J. Alloys Cmpds. 375 (2004) 98-106.

[12] D. B. Ravnsbæk, L. H. Rude, T. R. Jensen, J. Solid State Chem. 184 (2011) 1858-1866.

[13] J. E. Olsen, M. H. Sørby, B. C. Hauback, J. Alloys Compds. 509 (2011) L228-L231.

[14] M. Matsuo, S. Kuromoto, T. Sato, H. Oguchi, H. Takamura, S. Orimo, Appl. Phys. Lett. 100 (2012) 203904.

[15] R. D. Shannon, Acta Cryst. A 32 (1976) 751-767.

[16] N.B., the corresponding Shannon crystal radius of the $\mathrm{BH}_{4}{ }^{-}$anion was calculated from the $\mathrm{NaBH}_{4}$ lattice constant using the $\mathrm{VI}$-coordinate Shannon crystal radius of the $\mathrm{Na}^{+}$cation.

[17] All commercial suppliers in this paper are mentioned for clarity. This does not imply our recommendation or endorsement.

[18] A. Meyer, R. M. Dimeo, P. M. Gehring, D. A. Neumann, Rev. Sci. Instrum. 74 (2003) 27592777.

[19] J. R. D. Copley, J. C. Cook, Chem. Phys. 292 (2003) 477-485.

[20] T. J. Udovic, C. M. Brown, J. B. Leão, P. C. Brand, R. D. Jiggetts, R. Zeitoun, T. A. Pierce, I. Peral, J. R. D. Copley, Q. Huang, D. A. Neumann, R. J. Fields, Nucl. Instr. and Meth. A 588 (2008) 406-413.

[21] R. T. Azuah, L. R. Kneller, Y. Qiu, P. L. W. Tregenna-Piggott, C. M. Brown, J. R. D. Copley, R. M. Dimeo, J. Res. Natl. Inst. Stan. 114 (2009) 341-358.

[22] K. Momma and F. Izumi, J. Appl. Crystallogr. 44 (2011) 1272-1276.

[23] T. J. Udovic, N. Verdal, J. J. Rush, D. J. De Vries, M. R. Hartman, J. J. Vajo, A. F. Gross, A. V. Skripov, J. Alloys Compds. 580 (2013) S47-S50.

[24] P. Martelli, A. Remhof, A. Borgschulte, R. Ackermann, T. Strässle, J. P. Embs, M. Ernst, M. Matsuo, S. Orimo, Andreas Züttel, J. Phys. Chem. A 115 (2011) 5329-5334.

[25] A. V. Skripov, A. V. Soloninin, L. H. Rude, T. R. Jensen, Y. Filinchuk, J. Phys. Chem. C 116 (2012) 26177-26184.

[26] A. Remhof, Z. Łodziana, F. Buchter, P. Martelli, F. Pendolino, O. Friedrichs, A. Züttel, J. P. Embs, J. Phys. Chem. C 113 (2009) 16834-16837.

[27] N. Verdal, M. R. Hartman, T. Jenkins, D. J. DeVries, J. J. Rush, T. J. Udovic, J. Phys. Chem. C 114 (2010) 10027-10033. 
[28] M. Bée, Quasielastic Neutron Scattering, Principles and Applications in Solid State Chemistry, Biology and Materials Science, Adam Hilger, Bristol, 1988.

[29] K. Sköld, J. Chem. Phys. 49 (1968) 2443-2445.

[30] J. J. Rush, L. A. d. Graaf, R. C. Livingston, J. Chem. Phys. 58 (1973) 3439-3447. 


\section{Figure Captions}

Figure 1. Schematic of the $\mathrm{BH}_{4}{ }^{-}$anion centered within the disordered fcc lattice of $\mathrm{NaBH}_{4}-\mathrm{NaX}$ $\left(\mathrm{X}=\mathrm{Cl}, \mathrm{BH}_{4}\right.$, or $\left.\mathrm{I}\right)$. $\mathrm{Na}, \mathrm{X}, \mathrm{B}$, and $\mathrm{H}$ are denoted by gold, large green, small green, and white spheres, respectively. It is assumed that all $\mathrm{BH}_{4}{ }^{-}$anions possess diffraction-average orientational disorder between two positions as observed for $\mathrm{NaBH}_{4}$ above $190 \mathrm{~K}$, resulting in $50 \% \mathrm{H}$ atom occupation of the eight cube corners.

Figure 2. A comparison of neutron elastic scattering fixed-window scans for $\mathrm{NaBH}_{4}-\mathrm{NaCl}$ (blue) and $\mathrm{NaBH}_{4}$-Nal (red), summed over all detectors $\left(0.2 \AA^{-1}<Q<1.75 \AA^{-1}\right)$ and both offset and scaled appropriately to align all data at both low and high temperatures.

Figure 3. EISF vs. $Q$ data for $\mathrm{NaBH}_{4}-\mathrm{NaCl}$ and $\mathrm{NaBH}_{4}-\mathrm{Nal}$ at several temperatures in comparison with various curves associated with different jump reorientation models (in descending order): two-fold and/or three-fold uniaxial jumps (blue), tetrahedral tumbling (black), cubic tumbling (green), and isotropic rotational diffusion (purple).

Figure 4. Arrhenius plots of quasielastic linewidth (HWHM) vs. $T^{1}$ for $\mathrm{NaBH}_{4}-\mathrm{NaCl}$ (blue) and $\mathrm{NaBH}_{4}-\mathrm{Nal}$ (red) in comparison with that observed previously for $\mathrm{NaBH}_{4}$ (black, from [27]) in its disorder cubic phase. The three lowest-temperature points for $\mathrm{NaBH}_{4}-\mathrm{Nal}$ were measured on HFBS. Activation energies for reorientation are extracted from the slopes.

Figure 5. A comparison of neutron vibrational spectra at $4 \mathrm{~K}$ for $\mathrm{NaBH}_{4}-\mathrm{NaCl}$ (blue), $\mathrm{NaBH}_{4}$ (black, data above 32 meV from [27]), and $\mathrm{NaBH}_{4}-\mathrm{Nal}$ (red). 


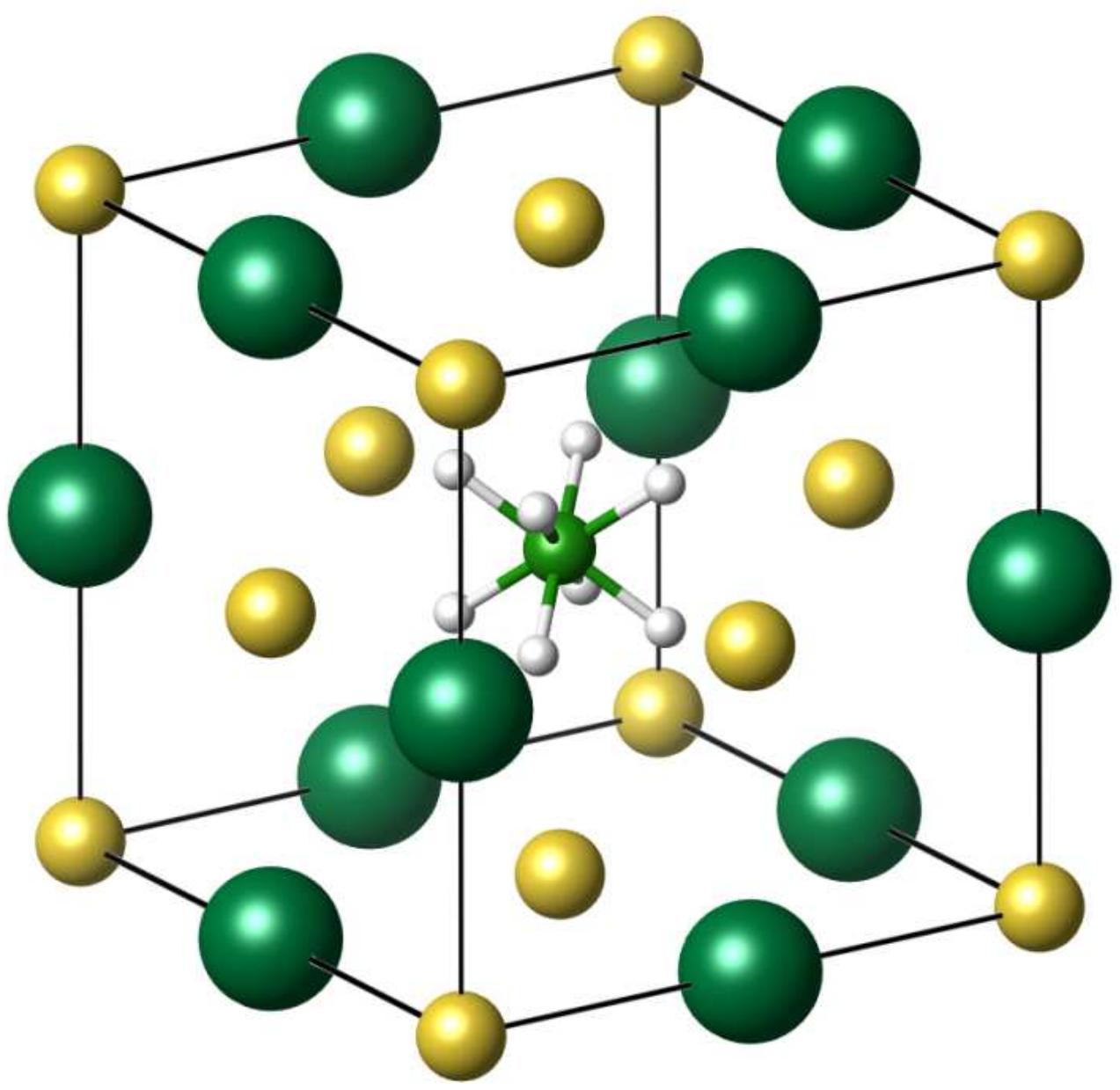

Figure 1. Schematic of the $\mathrm{BH}_{4}{ }^{-}$anion centered within the disordered fcc lattice of $\mathrm{NaBH}_{4}-\mathrm{NaX}$ $\left(\mathrm{X}=\mathrm{Cl}, \mathrm{BH}_{4}\right.$, or $\left.\mathrm{I}\right)$. $\mathrm{Na}, \mathrm{X}, \mathrm{B}$, and $\mathrm{H}$ are denoted by gold, large green, small green, and white spheres, respectively. It is assumed that all $\mathrm{BH}_{4}^{-}$anions possess diffraction-average orientational disorder between two positions as observed for $\mathrm{NaBH}_{4}$ above $190 \mathrm{~K}$, resulting in $50 \% \mathrm{H}$ atom occupation of the eight cube corners. 


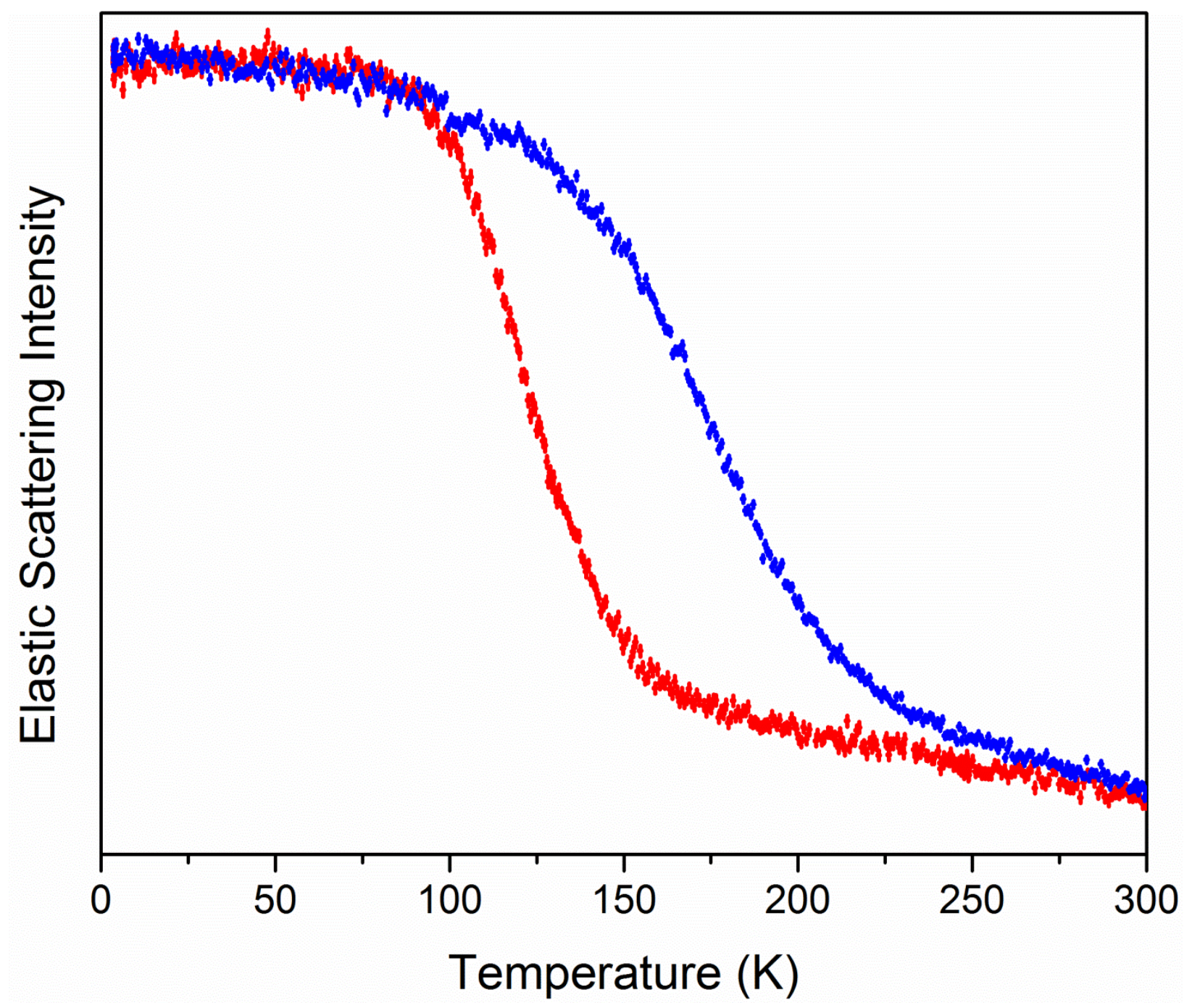

Figure 2. A comparison of neutron elastic scattering fixed-window scans for $\mathrm{NaBH}_{4}-\mathrm{NaCl}$ (blue) and $\mathrm{NaBH}_{4}$-Nal (red), summed over all detectors $\left(0.2 \AA^{-1}<Q<1.75 \AA^{-1}\right)$ and both offset and scaled appropriately to align all data at both low and high temperatures. 


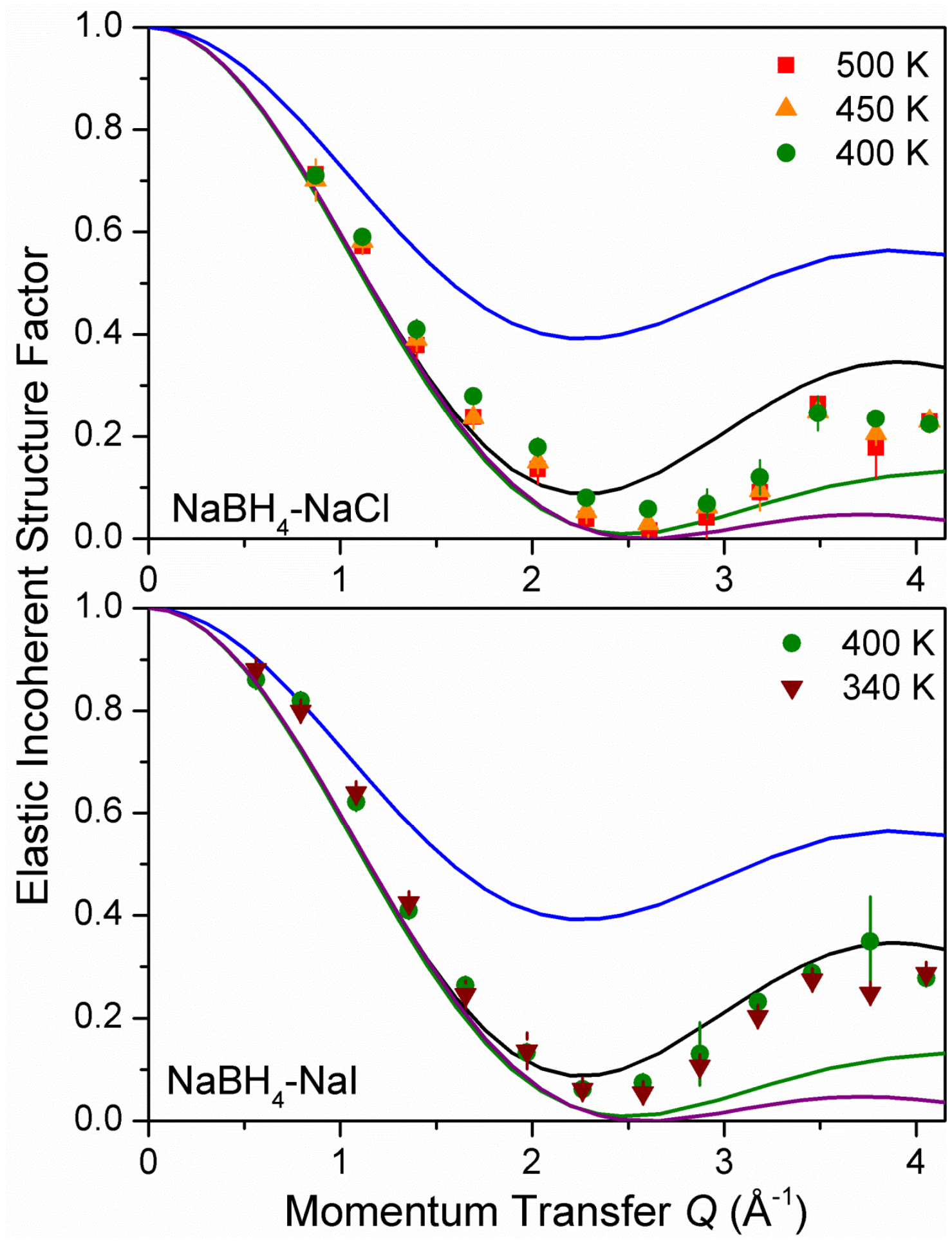

Figure 3. EISF vs. $\mathrm{Q}$ data for $\mathrm{NaBH}_{4}-\mathrm{NaCl}$ and $\mathrm{NaBH}_{4}-\mathrm{Nal}$ at several temperatures in comparison with various curves associated with different jump reorientation models (in descending order): two-fold and/or three-fold uniaxial jumps (blue), tetrahedral tumbling (black), cubic tumbling (green), and isotropic rotational diffusion (purple). 


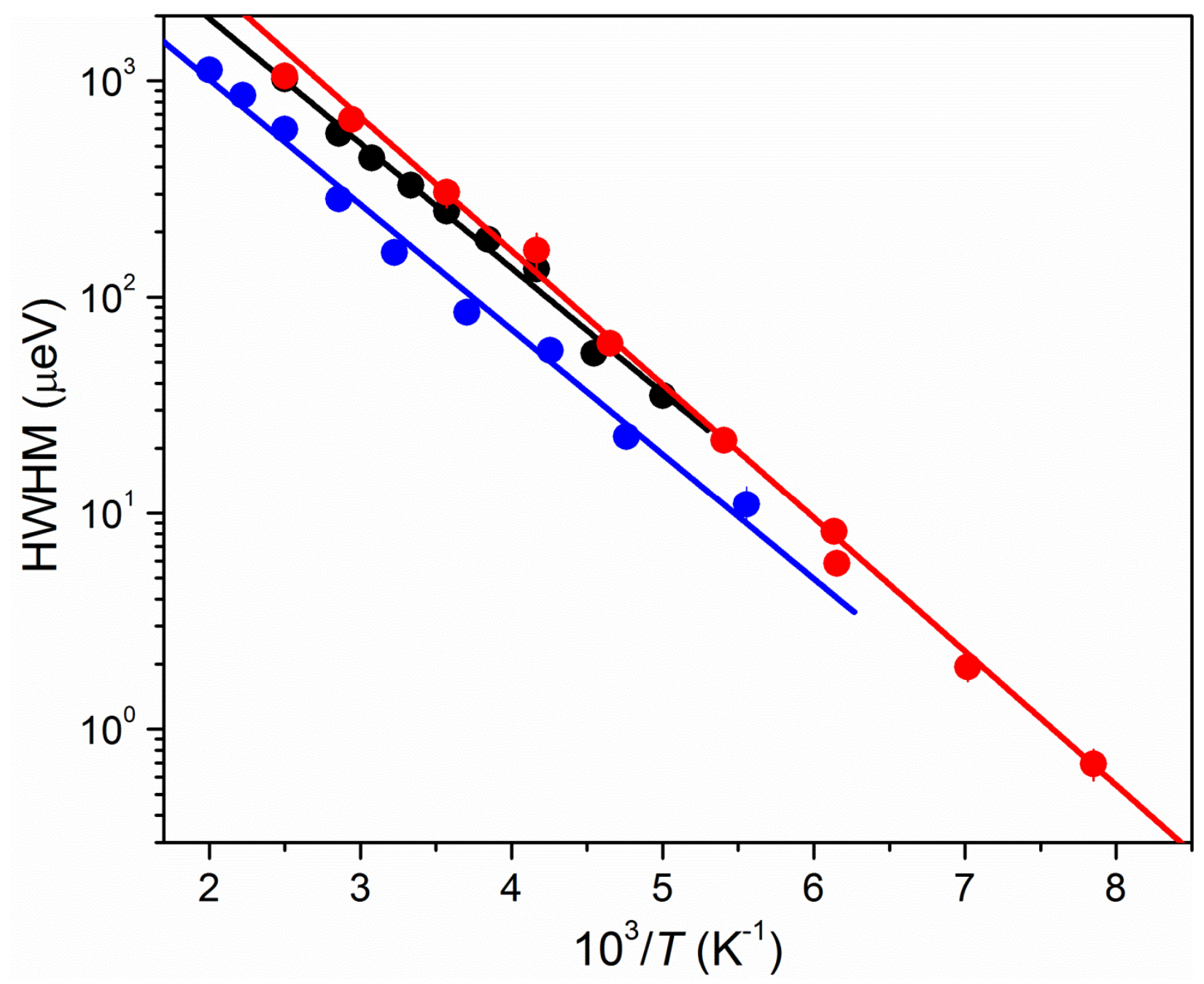

Figure 4. Arrhenius plots of quasielastic linewidth (HWHM) vs. $T^{-1}$ for $\mathrm{NaBH}_{4}-\mathrm{NaCl}$ (blue) and $\mathrm{NaBH}_{4}-\mathrm{Nal}$ (red) in comparison with that observed previously for $\mathrm{NaBH}_{4}$ (black, from [27]) in its disorder cubic phase. The three lowest-temperature points for $\mathrm{NaBH}_{4}-\mathrm{Nal}$ were measured on HFBS. Activation energies for reorientation are extracted from the slopes. 


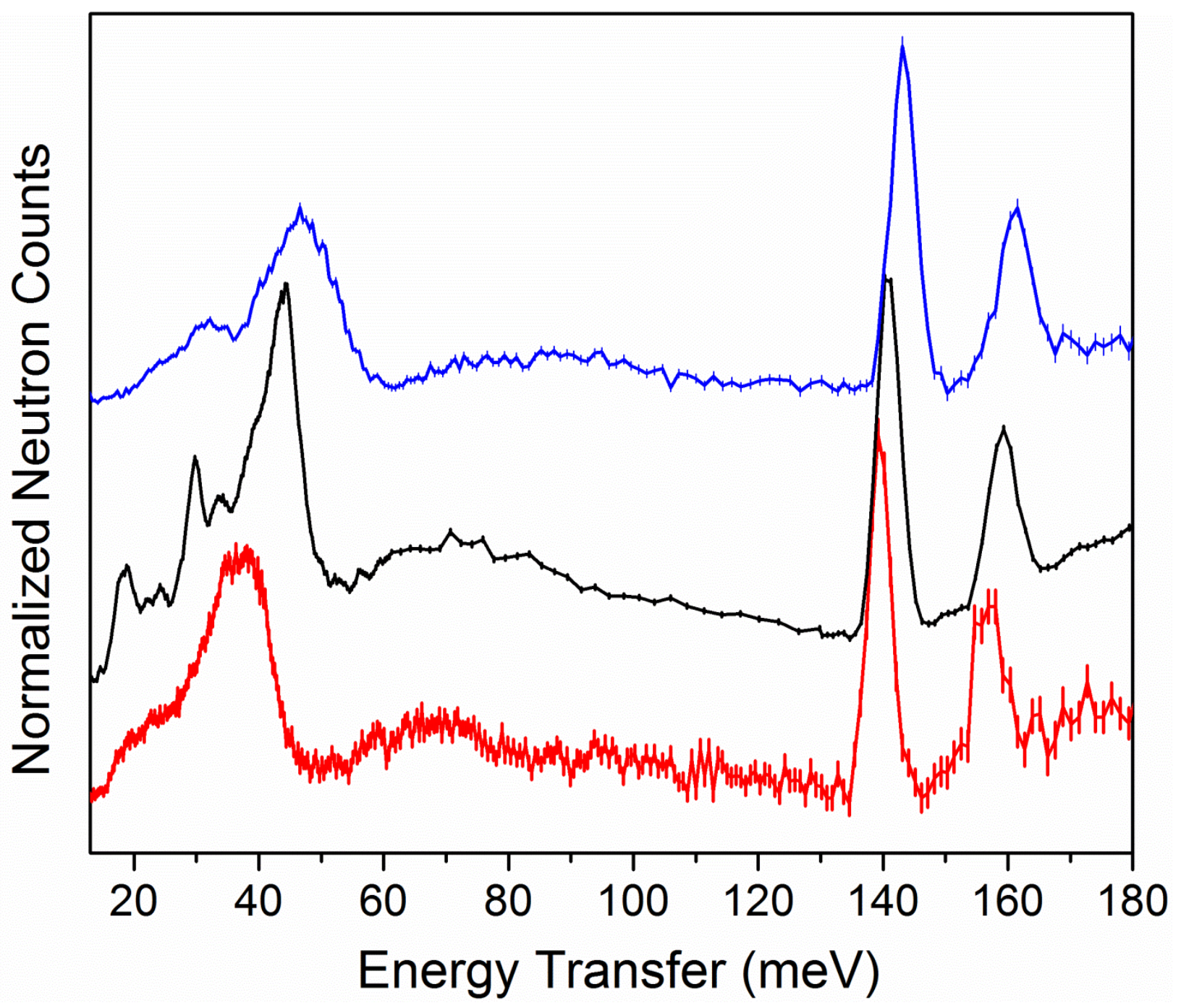

Figure 5. A comparison of neutron vibrational spectra at $4 \mathrm{~K}$ for $\mathrm{NaBH}_{4}-\mathrm{NaCl}$ (blue), $\mathrm{NaBH}_{4}$ (black, data above $32 \mathrm{meV}$ from [27]), and $\mathrm{NaBH}_{4}-\mathrm{Nal}$ (red). 


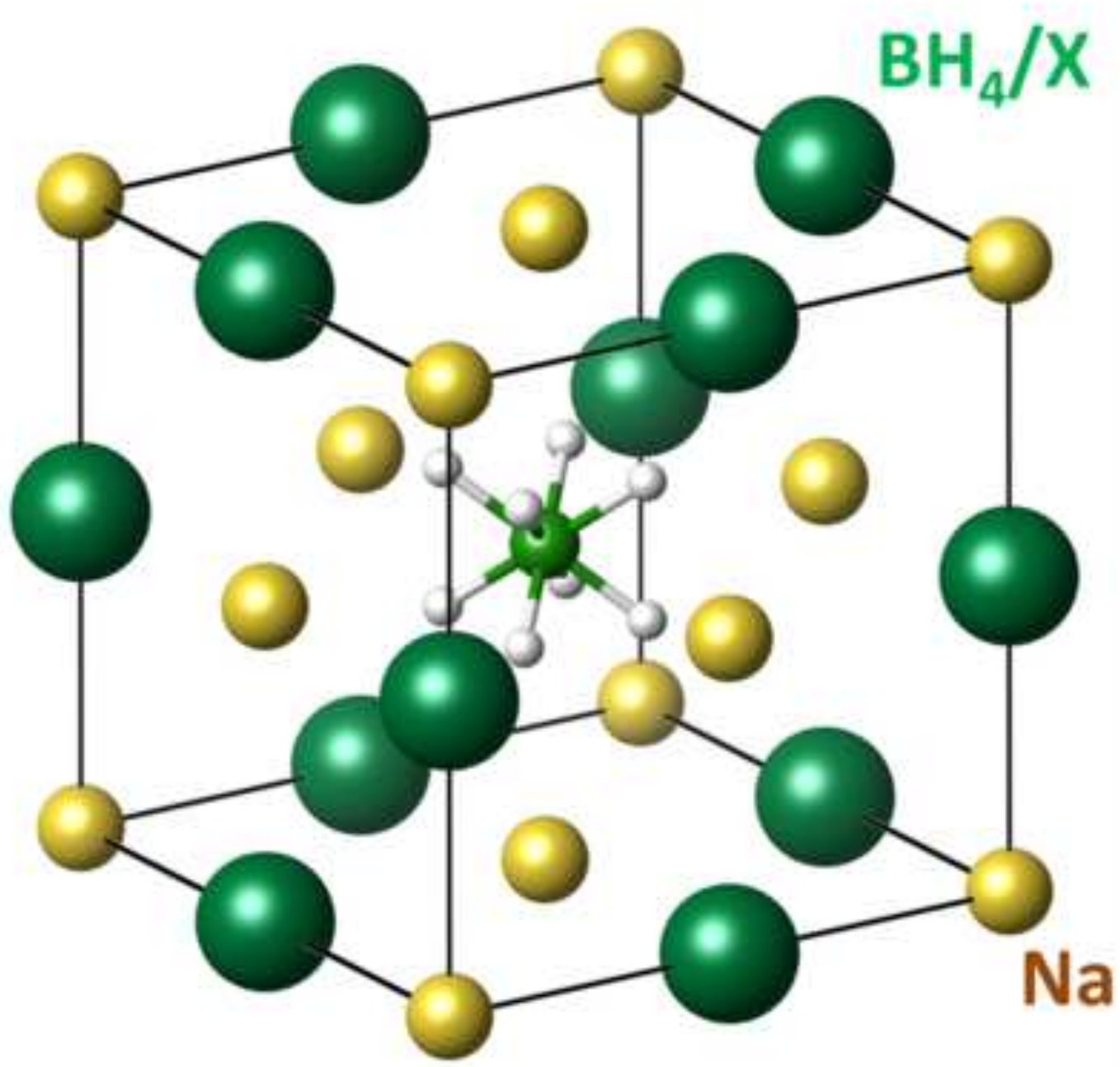

$\mathrm{NaBH}_{4}-\mathrm{NaX}(\mathrm{X}=\mathrm{Cl}, \mathrm{I})$ Solid Solution

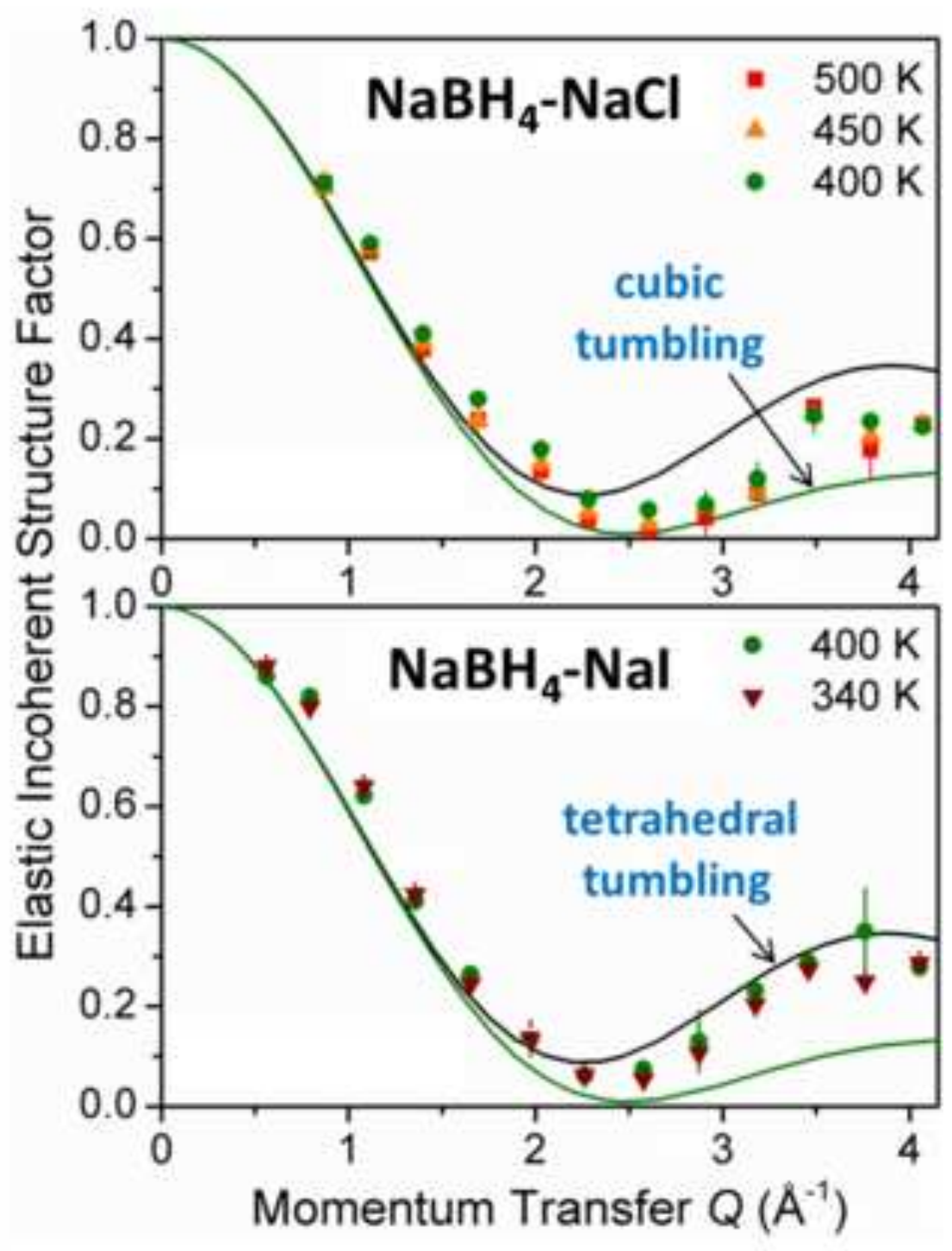

